Marquette University

e-Publications@Marquette

Psychology Faculty Research and Publications

Psychology, Department of

9-1-2009

\title{
Modulation of Long-Term Memory by Arousal in Alexithymia: The Role of Interpretation
}

Kristy A. Nielson

Marquette University, kristy.nielson@marquette.edu

Mitchell A. Meltzer

Marquette University

NOTICE: this is the author's version of a work that was accepted for publication in Consciousness and Cognition. Changes resulting from the publishing process, such as peer review, editing, corrections, structural formatting, and other quality control mechanisms may not be reflected in this document. Changes may have been made to this work since it was submitted for publication. A definitive version was subsequently published in Consciousness and Cognition, Vol. 18, No. 3 (September 2009):

786-793. DOI. (c) 2009 Elsevier. Used with permission. 


\title{
Modulation of long-term memory by arousal in alexithymia: The role of interpretation
}

\author{
Kristy A. Nielson \\ Department of Psychology, Marquette University \\ Milwaukee, Wisconsin \\ Mitchell A. Meltzer \\ Department of Psychology, Marquette University \\ Milwaukee, Wisconsin
}

\begin{abstract}
Moderate physiological or emotional arousal induced after learning modulates memory consolidation, helping to distinguish important memories from trivial ones. Yet, the contribution of subjective awareness or interpretation of arousal to this effect is uncertain. Alexithymia, which is an inability to describe or identify one's emotional and arousal states even though physiological responses to arousal are intact, provides a tool to evaluate the role of arousal interpretation. Participants scoring high and low on alexithymia ( $N=30$ each) learned a list of 30 words, followed by immediate recall. Participants then saw either an arousing (oral surgery) or neutral video (tooth brushing). Memory was tested 24-h later. Physiological response to arousal was comparable between groups, but subjective response to arousal was impaired in high alexithymia. Yet, delayed word recognition was enhanced by arousal regardless of alexithymia status. Thus, subjective response to arousal, i.e., cognitive appraisal, was not necessary for memory modulation to occur.
\end{abstract}

[Consciousness and Cognition, Vol 18, No. 3 (September 2009): pg. 786-793. DOI. This article is (C) Elsevier and permission has been granted for this version to appear in e-Publications@Marquette. Elsevier does not grant permission for this article to be further copied/distributed or hosted elsewhere without the express permission from Elsevier.] 
Keywords: Memory modulation, Arousal interpretation, Memory consolidation, Alexithymia, Emotional awareness.

\section{Introduction}

Alexithymia is a construct describing a cluster of characteristics that includes difficulty identifying, describing, and communicating feelings; difficulty distinguishing between feelings and bodily sensations; constricted imaginal processes; and an externally oriented cognitive style (Sifneos, 1973; Taylor, 2000; Taylor, Bagby, \& Parker, 1991). Alexithymia is also a relatively stable trait under changing degrees of emotion, stress, and pathology (Luminet, Bagby, \& Taylor, 2001; Mikolajczak \& Luminet, 2006; Subic-Wrana, Bruder, Thomas, Lane, \& Kohle, 2005). Although its precise etiology is unknown, alexithymia has been postulated to be associated with emotional dysregulation (Taylor, 1994). As such, individuals with alexithymia lack awareness (i.e., subjective acknowledgment) of their emotional and arousal states and they tend to suffer from psychiatric and psychosomatic disorders at a high rate (e.g., Lumley, Stettner, \& Wehmer, 1996; Taylor \& Taylor, 1997).

The link between alexithymia and disease has been postulated to be due to prolonged exposure to adrenal hormones as a result of unacknowledged and unresolved stress and arousal (Chrousos, 1998; Martin \& Pihl, 1985; Papciak, Feuerstein, \& Spiegel, 1985). This postulation has received much support, in spite of differences across study methods and specific results (e.g., Friedlander, Lumley, Farchione, \& Doyal, 1997; Martin \& Pihl, 1986; Stone \& Nielson, 2001; Wehmer, Brejnak, Lumley, \& Stettner, 1995). For example, our experimental study showed that high alexithymia was associated with heightened baseline arousal level and intact physiological response to an arousing video clip of live-action oral surgery (Stone \& Nielson, 2001). However, subjective response to the clip was impaired in high alexithymia. Importantly, the distinction between subjective and physiological response to arousal in alexithymia may provide a valuable tool for investigating the role of emotion and arousal in memory consolidation.

[Consciousness and Cognition, Vol 18, No. 3 (September 2009): pg. 786-793. DOI. This article is (C) Elsevier and permission has been granted for this version to appear in e-Publications@Marquette. Elsevier does not grant permission for this article to be further copied/distributed or hosted elsewhere without the express permission from Elsevier.] 
Emotional and arousing events are recollected with greater frequency than similar but neutral events. This is likely an adaptive function, effectively highlighting important events toward protecting and preparing an organism for similar future events (McGaugh, 2000). Memory consolidation, believed to underlie this highlighting process, is the outcome of a complex set of neurobiological processes occurring after the initial formation of a memory (McGaugh, 2000; Müller \& Pilzecker, 1900; Nielson \& Powless, 2007; Revelle \& Loftus, 1992; Torras-Garcia, Portell-Cortes, Costa-Miserachs, \& Morgado-Bernal, 1997).

A variety of substances, including glucose and the adrenal hormones epinephrine and norepinephrine, are released into the bloodstream during times of arousal, stress and emotion, which indirectly alter brain stem and amygdalar function (Gold, 2005; Hamann, 2001; McGaugh, 2000; McGaugh, Cahill, \& Roozendaal, 1996). When administered soon after learning, these substances alter memory in a classic "inverted- $U$ " manner, whereby moderate amounts enhance performance and low or high amounts can impair or fail to influence performance (McGaugh, 2000; Yerkes \& Dodson, 1908). Although emotional events naturally involve arousal onset during the event itself, arousal typically also persists for some time afterward. Therefore, like other arousal sources, emotion can have physiological effects on memory consolidation, as well as on encoding and attention. Indeed, although arousal can facilitate detection and encoding for long-term retention, it can also hinder retrieval in the short-run and not reveal its enhancing effects for hours or even days (Kleinsmith \& Kaplan, 1963; Revelle \& Loftus, 1992; Torras-Garcia et al., 1997; Walker, 1958). These effects are also time-dependent, such that doses administered during or soon after learning are effective, but those administered after long intervals are ineffective (e.g., Gold \& van Buskirk, 1975; Nielson \& Powless, 2007).

The preponderance of human studies examining the effects of arousal on learning or memory have used either inherently emotional materials or other interventions given before or coincident with the learning task. As such, it is impossible to decipher in these studies whether the arousal effect is on attention, encoding, consolidation, or some combination of these memory phases. However, several recent studies have demonstrated memory modulatory effects in human

[Consciousness and Cognition, Vol 18, No. 3 (September 2009): pg. 786-793. DOI. This article is @ Elsevier and permission has been granted for this version to appear in e-Publications@Marquette. Elsevier does not grant permission for this article to be further copied/distributed or hosted elsewhere without the express permission from Elsevier.] 
participants by comparable mechanisms of action as have been shown in rodent studies. These studies have spanned a variety of tasks and post-learning treatments, including norepinephrine (Southwick et al., 2002), glucose (Manning, Parsons, \& Gold, 1992), nicotine (Colrain, Mangan, Pellett, \& Bates, 1992), and non-invasive treatments such as muscle tension (Nielson \& Jensen, 1994; Nielson, Radtke, \& Jensen, 1996), stress (Cahill, Gorski, \& Le, 2003), and negative and positive emotional arousal (Nielson \& Bryant, 2005; Nielson \& Powless, 2007; Nielson, Yee, \& Erickson, 2005).

Despite the extensive animal and growing human literatures on the biological foundations of memory modulation by arousal, a number of cognitive studies have not found significant effects of arousal manipulations on memory performance. Such null findings have led to the contention that arousal only influences memory if the arousal source is semantically related to the memoranda (e.g., Christianson \& Mjörndal, 1985; Varner \& Ellis, 1998) or if the memoranda are inherently arousing (Buchanan \& Lovallo, 2001; Cahill et al., 2003; Liu, Graham, \& Zorawski, 2008). These studies have greatly contributed to the discussion of emotion and memory. However, such conclusions were premature due to several limitations of these studies (cf. Nielson et al., 2005), including the use of very short delays before testing, which do not allow for the process of memory consolidation to occur (Kleinsmith \& Kaplan, 1963; McGaugh, 2000; Quevedo et al., 2003; Revelle \& Loftus, 1992; Torras-Garcia et al., 1997; Walker, 1958).

Moreover, the semantic relatedness contention about arousal does not consider the growing number of studies demonstrating that arousal that is induced after learning modulates long-term memory for materials that have no semantic relation to the arousal stimulus (Colrain et al., 1992; Manning et al., 1992; Nielson \& Bryant, 2005; Nielson \& Jensen, 1994; Nielson \& Powless, 2007; Nielson et al., 1996, 2005; Southwick et al., 2002). Therefore, there would be a benefit to the literature from studies designed to dissociate the effects of physiological arousal response from the effects of arousal interpretation on memory. Alexithymia presents a unique opportunity to test this idea because of the inherent dissociation of arousal response from its interpretation. That is, studies of participants who endorse high and low alexithymia tendencies present the opportunity 
to evaluate whether memory modulation by arousal is influenced by impaired subjective, but not physiological, response to arousal.

Cognitive abilities have not been often empirically studied in alexithymia, and memory modulation has been entirely unstudied in alexithymia. However, in line with intact physiological responding in alexithymia, a recent visual evoked potential study demonstrated intact perceptual processing of emotional and neutral pictures by alexithymics (Franz, Schaefer, Schneider, Sitte, \& Bachor, 2004). Yet, there are suggestions that the cognitive schemas necessary for processing the meaning of emotion are deficient in alexithymia (Taylor, Bagby, \& Parker, 1997). Consistent with this notion, one study found increased Stroop interference in alexithymia for illness words relative to negative emotion words, but not relative to neutral words (Lundh \& Simonsson-Sarnecki, 2002).

A few recent studies have also examined memory performance in alexithymia, with mixed results. For example, one study demonstrated that both positive and negative autobiographical memories were equally well recalled in high and low alexithymia (Lundh, Johnsson, Sundqvist, \& Olsson, 2002). However, another study found no alexithymia differences in recall of neutral words or emotion words that were only characterized by a feeling of knowing ("know"), but high alexithymia participants recalled significantly fewer emotion words that could be recollected with contextual detail ("remember", Luminet, Vermeulen, Demaret, Taylor, \& Bagby, 2006). Finally, one study demonstrated that those with high alexithymia had reduced implicit memory for positive emotion words (Suslow, Kersting, \& Arolt, 2003). Thus, although little study of memory in alexithymia has been yet undertaken, the available results suggest memory may be normal for neutral stimuli. Results are mixed regarding emotive stimuli. Yet, these studies used only immediate tests of memory retrieval; long-term retrieval in alexithymia remains unstudied.

Therefore, the purpose of the current study was to evaluate long-term memory in alexithymia with neutral stimuli. Specifically, the purpose was to examine whether arousal-induced memory modulation occurs comparably in high and low alexithymia, toward determining whether subjective awareness of arousal state influences memory modulation. The design was based upon that used in our previous

[Consciousness and Cognition, Vol 18, No. 3 (September 2009): pg. 786-793. DOI. This article is (C) Elsevier and permission has been granted for this version to appear in e-Publications@Marquette. Elsevier does not grant permission for this article to be further copied/distributed or hosted elsewhere without the express permission from Elsevier.] 
alexithymia study (Stone \& Nielson, 2001), with the addition of a memory task. Briefly, prospective participants $(>300)$ were screened using the Toronto Alexithymia Scale-20 (TAS-20; Bagby, Parker, \& Taylor, 1994; Bagby, Taylor, \& Parker, 1994). Those scoring in the top and bottom quintiles ( $n=30$ each) viewed a 30-noun word list, after which recall was tested. Afterward, either an arousing (oral surgery) or neutral (tooth brushing) video clip was presented (Nielson et al., 2005; Stone \& Nielson, 2001), with quasi-random assignment to groups. Recognition was tested $24 \mathrm{~h}$ later, with scores corrected for guessing (see Supplementary materials for detailed methods). It was hypothesized that arousal after learning would enhance delayed retrieval (e.g., Nielson \& Bryant, 2005; Nielson \& Jensen, 1994; Nielson \& Powless, 2007; Nielson et al., 1996, 2005). Moreover, because high alexithymia was expected to be associated with intact physiological response to arousal despite impaired subjective response (Stone \& Nielson, 2001), it was further hypothesized that alexithymia would not differentiate or interact with memory performance.

\section{Results}

\subsection{Descriptive statistics}

There were no significant group differences for vocabulary, the PSS, the BDI, the BAI, baseline EDA, or baseline heart rate (all effects, ps $>.21$, see Table 1). Notably, baseline heart rate and EDA were, however, generally higher in high alexithymia. Immediate recall performance (tested prior to arousal induction) did differ between TAS groups, such that high-alexithymics (mean $=33.9 \%, \operatorname{SEM}=1.8$ ) recalled fewer words than did low-alexithymics (mean $=39.4 \%$, SEM $=1.8)$, TAS: $F(1,56)=4.80, p=.033, \eta^{2}=.079$. However, there was no difference by tape (arousal) group, Tape: $F(1,56)=1.11, p=.30, \eta^{2}=.019$;

Tape $\times$ TAS: $F(1,56)=0.035, p=.85, \eta^{2}=.001$.

[Consciousness and Cognition, Vol 18, No. 3 (September 2009): pg. 786-793. DOI. This article is @ Elsevier and permission has been granted for this version to appear in e-Publications@Marquette. Elsevier does not grant permission for this article to be further copied/distributed or hosted elsewhere without the express permission from Elsevier.] 
NOT THE PUBLISHED VERSION; this is the author's final, peer-reviewed manuscript. The published version may be accessed by following the link in the citation at the bottom of the page.

Table 1. Descriptive statistics (mean \pm SD) for high- and low-alexithymia groups in the high- and low-arousal experimental groups.

\begin{tabular}{lllll} 
Measure & $\begin{array}{l}\text { High TAS } \\
\text { arousal } \\
(\boldsymbol{N}=\mathbf{1 4})\end{array}$ & $\begin{array}{l}\text { Low TAS } \\
\text { arousal } \\
(\boldsymbol{N}=\mathbf{1 3})\end{array}$ & $\begin{array}{l}\text { High TAS } \\
\text { neutral } \\
(\mathbf{N}=\mathbf{1 6})\end{array}$ & $\begin{array}{l}\text { Low TAS } \\
\text { neutral } \\
(\boldsymbol{N}=\mathbf{1 7})\end{array}$ \\
\hline $\begin{array}{l}\text { Gender } \\
7 \mathrm{~F}, 7 \mathrm{M}\end{array}$ & $9 \mathrm{~F}, 4 \mathrm{M}$ & $10 \mathrm{~F}, 6 \mathrm{M}$ & $11 \mathrm{~F}, 6 \mathrm{M}$ \\
TAS score & $59.5(5.4)$ & $31.2(4.3)$ & $60.8(8.9)$ & $31.8(3.6)$ \\
Vocabulary & $46.7(9.6)$ & $48.2(8.2)$ & $49.5(7.2)$ & $46.7(9.6)$ \\
PSS & $46.3(4.0)$ & $48.3(4.8)$ & $46.1(3.6)$ & $46.9(4.2)$ \\
BDI & $6.6(5.5)$ & $6.0(6.6)$ & $7.4(6.0)$ & $5.5(5.1)$ \\
BAI & $6.6(4.7)$ & $5.3(3.0)$ & $8.6(6.0)$ & $6.7(5.1)$ \\
$\begin{array}{l}\text { Immediate } \\
\text { recall (\%) }\end{array}$ & $35.0(11.0)$ & $41.0(10.1)$ & $32.8(8.7)$ & $37.9(9.2)$ \\
$\begin{array}{l}\text { Baseline heart } \\
\text { rate (BPM) }\end{array}$ & $69.5(12.4)$ & $71.8(10.5)$ & $71.1(12.3)$ & $68.7(9.2)$ \\
$\begin{array}{l}\text { Baseline EDA } \\
\text { (micro mho) }\end{array}$ & $10.3(4.2)$ & $9.3(5.7)$ & $8.5(4.3)$ & $7.5(4.5)$
\end{tabular}

F, female; M, male; TAS, Toronto Alexithymia Scale; arousal/neutral, experimental condition imposed after learning; vocabulary, raw score on the WAIS-R vocabulary subtest; PSS, Perceived Stress Scale; BDI, Beck Depression Inventory; BAI, Beck Anxiety Inventory; immediate recall was measured prior to the arousal manipulation; BPM, beats per minute; EDA, electrodermal activity (skin conductance). There were no significant differences between groups.

\section{2. $E D A$}

Three-way mixed ANOVA for EDA indicated a significant main effect of measures, showing overall change from baseline, $F(1,56)=18.21, p<.001, \eta^{2}=.245$. In addition there was a main effect of arousal tape (Tape: $F(1,56)=4.62, p=.036, \eta^{2}=.076$ ) and a measures by tape interaction, indicating that those watching the arousal tape demonstrated significant elevation in skin conductance relative to those who watched the neutral tape, $F(1,56)=7.92, p=.007, \eta^{2}=.124$ (see Fig. 1 A; arousal $p<.001$, non-arousal $p=.28$ ). Although the high alexithymia groups tended to have higher baseline values, there were no significant effects involving TAS group, Measures $\times$ TAS: $F(1,56)=2.47, p=.12, \eta^{2}=.042$; Measures $\times$ Tape $\times$ TAS: $F(1,56)=0.89, p=.77, \eta^{2}=.002$;

[Consciousness and Cognition, Vol 18, No. 3 (September 2009): pg. 786-793. DOI. This article is (C) Elsevier and permission has been granted for this version to appear in e-Publications@Marquette. Elsevier does not grant permission for this article to be further copied/distributed or hosted elsewhere without the express permission from Elsevier.] 
NOT THE PUBLISHED VERSION; this is the author's final, peer-reviewed manuscript. The published version may be accessed by following the link in the citation at the bottom of the page.

TAS: $F(1,56)=1.45, p=.23, \eta^{2}=.025$;

Tape $\times$ TAS: $F(1,56)=0.004, p=.95, \eta^{2}=.00$.

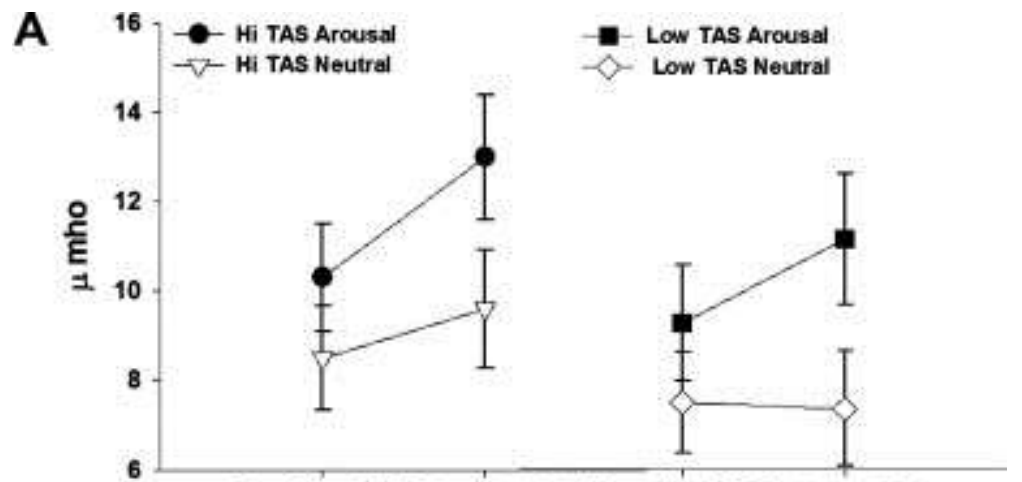

Baseline EDA Tape EDA Baseline EDA Tape EDA

B
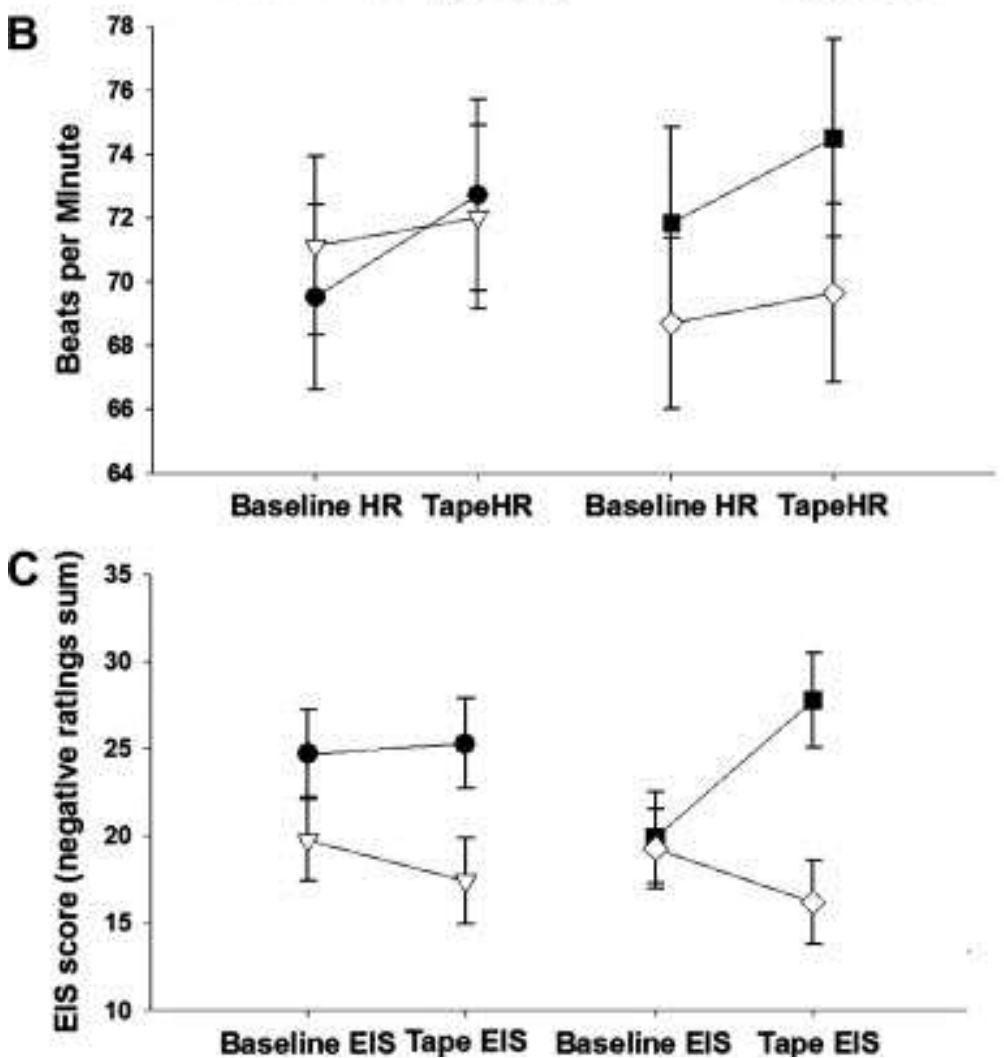

Fig. 1. Mean ( \pm SEM) electrodermal activity (EDA, Panel $A)$ and heart rate (Panel $B)$, and subjective arousal ratings (emotional intensity score, EIS, Panel C) for high- and low-alexithymia groups (TAS) at baseline and after the high- or low-arousal manipulation. Both alexithymia groups who watched the arousing video had significant elevations in skin conductance and heart rate. However, only low alexithymia participants exhibited a significant increase in subjective arousal after the arousing tape. 


\subsection{Heart rate}

Three-way mixed ANOVA for heart rate indicated a significant main effect of measures, showing overall change from baseline, $F(1,56)=20.00, p<.001, \eta^{2}=.263$. There was also a significant measures by tape interaction, indicating significant elevation of heart rate after watching the arousal tape, relative to those who watched the neutral tape, $F(1,56)=5.42, p=.024, \eta^{2}=.088$ (see Fig. 1B; arousal $p<.001$, non-arousal $p=.12$ ). There were no other significant effects, including no significant effects involving TAS group, Tape: $F(1,56)=0.37, p=.55, \eta^{2}=.007$;

Measures $\times$ TAS: $F(1,56)=0.065, p=.80, \eta^{2}=.001$;

Measures $\times$ Tape $\times$ TAS $F(1,56)=0.10, p=.75, \eta^{2}=.002$;

TAS: $F(1,56)=0.003, p=.96, \eta^{2}=.00$;

Tape $\times$ TAS: $F(1,56)=0.60, p=.44, \eta^{2}=.011$.

\subsection{Subjective arousal}

Three-way mixed ANOVA for subjective arousal ratings indicated a significant main effect of tape, $F(1,56)=7.25, p=.009, \eta^{2}=.115$, a significant measures by tape interaction, $F(1,56)=13.81, p<.001, \eta^{2}=.198$, and a significant measures by tape by TAS interaction, $F(1,56)=4.68, p=.035, \eta^{2}=.077$. The three-way interaction and a priori contrasts showed that although viewing the arousal tape caused elevated subjective arousal relative to the neutral tape, this effect occurred only in low alexithymia $(p<.001)$; the other three groups did not significantly change (low TAS non-arousal declined non-significantly, $p=.08$; high TAS non-arousal, $p=.20$; high TAS arousal, $p=.77$; see Fig. $1 \mathrm{C}$ ). Although the high alexithymia arousal group appeared to have somewhat higher baseline EIS than the other groups, the difference was not significant in any contrast (ps $>.12$ ). No other effects reached significance, Measures: $F(1,56)=0.64, p=.43, \eta^{2}=.01$;

TAS: $F(1,56)=0.19, p=.67, \eta^{2}=.003$;

Measures $\times$ TAS: $F(1,56)=3.03, p=.087, \eta^{2}=.051$;

Tape $\times$ TAS: $F(1,56)=0.004, p=.95, \eta^{2}=.00$.

[Consciousness and Cognition, Vol 18, No. 3 (September 2009): pg. 786-793. DOI. This article is @ Elsevier and permission has been granted for this version to appear in e-Publications@Marquette. Elsevier does not grant permission for this article to be further copied/distributed or hosted elsewhere without the express permission from Elsevier.] 


\subsection{Delayed recognition memory}

A 2 (TAS group) $\times 2$ (Tape) ANCOVA, using immediate recall as a covariate, revealed a significant main effect of tape, such that those who saw the arousal video after learning remembered significantly more words than did those who saw the neutral tape, $F(1,55)=12.27, p=.001, \eta^{2}=.182$ (see Fig. 2). No other effects were significant, TAS: $F(1,56)=0.714, p=.402, \eta^{2}=.013$; Tape $\times$ TAS: $F(1,56)=0.712, p=.402, \eta^{2}=.013$. (Note: the results were comparable when the covariate is not included.) A priori contrasts further confirmed these findings. The contrasts between arousal and non-arousal groups were significant for both low alexithymia $(p=.05)$ and high alexithymia $(p=.002)$, but the contrasts across alexithymia group did not differ within the arousal $(p=.99)$ or non-arousal $(p=.21)$ condition (see Fig. 2 ).

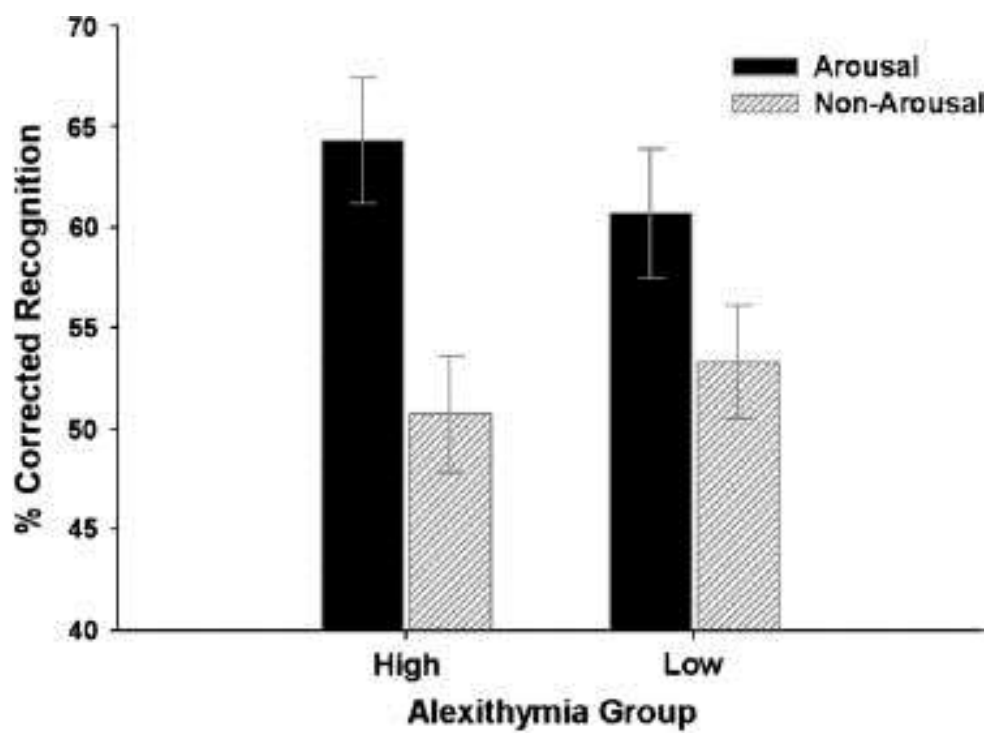

Fig. 2. Mean ( \pm SEM) corrected recognition performance for high- and low-alexithymia participants in the high- and low-arousal experimental groups. Arousal-induced after learning significantly enhanced 24-h word recognition performance in both high- and low-alexithymia groups.

\section{Discussion}

The purpose of the present study was to investigate short- and long-term memory for neutral words in alexithymia, as well as whether or not conscious arousal awareness is necessary for that arousal to modulate long-term memory consolidation. The latter goal was indirectly tested by comparing participants who were high or low in 
alexithymia on their 24-h delayed recognition of a word list whose presentation had been followed by either an arousing or neutral stimulus. The results of this study demonstrated that high alexithymia led to reduced immediate recall but unimpaired long-term recognition of the words. Furthermore, physiological arousal induced soon after learning modulated long-term memory regardless of alexithymia status.

Some previous studies, including our own, have supported elevated tonic arousal in alexithymia (e.g., Martin \& Pihl, 1986; Stone \& Nielson, 2001). The current findings were in the direction of supporting heightened tonic arousal in alexithymia, but the group differences did not reach significance. The methods of the current study were quite consistent with our previous study, and the results were in the same direction. However, while the previous study demonstrated higher baseline EDA in alexithymia, the current study demonstrated only a trend $(p=.12)$. Both studies showed heart rate in the direction of higher baselines in alexithymia but neither demonstrated statistical significance. The reason for the lack of replication is unclear, but the between subjects variability was greater in the present study than in the previous study. The previous literature has also been mixed on the issue of elevated baseline arousal in alexithymia, indicating wide differences in variability (e.g., Friedlander et al., 1997; Näätänen, Ryynänen, \& Keltikangas-Järvinen, 1999; Newton \& Contrada, 1994; Roedema \& Simons, 1999).

The current study also demonstrated that subjective arousal response to an emotional stimulus was impaired in high alexithymia, but physiological arousal response was comparable between alexithymia groups. This finding is consistent with our previous study (Stone \& Nielson, 2001) and it supports others that showed a "decoupling" of subjective response from physiological response to arousal in alexithymia (e.g., Friedlander et al., 1997; Martin \& Pihl, 1986; Papciak et al., 1985). Yet, the issue of physiological reactivity to arousal in alexithymia is far from settled. Some studies demonstrated enhanced physiological reactivity in alexithymia (e.g., Infrasca, 1997), while others have demonstrated reduced physiological reactivity (e.g., Linden, Lenz, \& Stossel, 1996; Newton \& Contrada, 1994). The inconsistencies across studies may be due to the fairly vast differences between studies in the measures of physiological arousal used, as well

[Consciousness and Cognition, Vol 18, No. 3 (September 2009): pg. 786-793. DOI. This article is (C Elsevier and permission has been granted for this version to appear in e-Publications@Marquette. Elsevier does not grant permission for this article to be further copied/distributed or hosted elsewhere without the express permission from Elsevier.] 
as the stimulus types used to provoke a response. Indeed, the type of stimulus, task requirements, and response strategy employed by the participant can cause either heart rate acceleration or deceleration in response to emotion or arousal (e.g., Coles, Jennings, \& Stern, 1984; Lacey, Kagan, Lacey, \& Moss, 1963; Lang, Greenwald, Bradley, \& Hamm, 1993; Obrist, 1981; Öhmann, Hamm, \& Hugdahl, 2000). Furthermore, the pattern of autonomic response differs with these variables across measurement indices as well (cf. Berntson, Cacioppo, \& Quigley, 1991). Thus, while some studies of arousing tasks in alexithymia have shown heart rate reductions using tasks such as anger recall (e.g., Neumann, Sollers, Thayer, \& Waldstein, 2004), our study used the viewing of a film clip that has consistently demonstrated increased heart rate response in previous studies (Nielson et al., 2005; Stone \& Nielson, 2001).

While baseline subjective arousal might appear higher in alexithymia (in the high arousal group only), it was not significantly higher than in any other group. Additionally, these scores were considerably below the upper range of scores in the responding low alexithymia group (see Fig. 1C). Thus, the lack of subjective response to arousal in this group is not likely attributable to a ceiling effect. Instead, the slightly higher subjective arousal baseline and lack of responsiveness in high alexithymia replicates our previous study (Stone \& Nielson, 2001). Indeed, our previous study demonstrated a nearly identical flat response in the high alexithymia group, although there was less baseline discrepancy.

With respect to memory, the current study demonstrated that immediate word recall was impaired in high alexithymia, while longterm (24-h) retrieval was comparable in high and low alexithymia. Therefore, the results suggest that alexithymia might inhibit shortterm, but not long-term retrieval. Previous studies have not investigated long-term retrieval in alexithymia. One short-term study using neutral stimuli found no effects of alexithymia, instead reporting that alexithymia impaired retrieval only when emotion words had to be retrieved with contextual detail (Luminet et al., 2006). Future studies are therefore needed to examine both short- and long-term delayed retrieval tests in alexithymia without memory modulation, and with and without emotive stimuli, in order to further investigate the memory effects of alexithymia.

[Consciousness and Cognition, Vol 18, No. 3 (September 2009): pg. 786-793. DOI. This article is @ Elsevier and permission has been granted for this version to appear in e-Publications@Marquette. Elsevier does not grant permission for this article to be further copied/distributed or hosted elsewhere without the express permission from Elsevier.] 
The results of the present study are also consistent with a number of previous studies that demonstrated significant enhancement of delayed retrieval when arousal was induced soon after learning (Colrain et al., 1992; Manning et al., 1992; Nielson \& Bryant, 2005; Nielson \& Jensen, 1994; Nielson \& Powless, 2007; Nielson et al., 1996, 2005; Southwick et al., 2002). In contrast, our results were not consistent with the contention that the arousal source must be semantically associated with the memoranda (Christianson \& Mjörndal, 1985; Varner \& Ellis, 1998) or that arousal would only influence emotive stimuli (Buchanan \& Lovallo, 2001; Cahill et al., 2003; Liu et al., 2008). Indeed, alexithymics, who exhibited impaired ability to subjectively assess their arousal state in the context of normal physiological response to arousal, exhibited significant memory modulation that was comparable to that of those who endorse little alexithymia.

The onset of physiological arousal, including the release of substances such as glucose, and the adrenal hormones epinephrine and norepinephrine, is triggered during the early neural processing of emotional stimuli (cf. McGaugh, 1983), which prior research has shown to be intact in individuals high in alexithymia (Franz et al., 2004). That is, alexithymics have no perceptual deficit for emotional stimuli and they show comparable early processing characteristics as non-alexithymics. Yet, they appear to have inadequate schemas for determining the importance or meaning of such stimuli or how to respond to them (Franz et al., 2004; Taylor et al., 1997). We therefore contend that cognitive appraisal, which occurs somewhat later in time to the perceptual analysis (in non-alexithymics), does not mitigate the effects of the already initiated physiological arousal response on memory consolidation. Thus, the present results support the contention that physiological arousal modulates long-term memory consolidation with little contribution of the cognitive appraisal of such arousal contributing to the effect.

The current study used only neutral memoranda, leaving the question as to whether or not arousal would modulate long-term memory consolidation for arousing or emotional stimuli in alexithymia. The previous research that suggested memory impairments for emotional material in alexithymia (Luminet et al., 2006; Suslow et al., 2003) might be particularly meaningful given also the contention that

[Consciousness and Cognition, Vol 18, No. 3 (September 2009): pg. 786-793. DOI. This article is @ Elsevier and permission has been granted for this version to appear in e-Publications@Marquette. Elsevier does not grant permission for this article to be further copied/distributed or hosted elsewhere without the express permission from Elsevier.] 
arousal after learning might preferentially influence the retention of arousing stimuli (Buchanan \& Lovallo, 2001; Cahill et al., 2003; Liu et al., 2008). Although a comparable number of studies do not support this contention (Abercrombie, Kalin, Thurow, Rosenkranz, \& Davidson, 2003; Lupien et al., 2002; Maheu, Joober, Beaulieu, \& Lupien, 2004), studies specifically addressing it in alexithymia are warranted.

In summary, high alexithymia led to impaired immediate recall of words, but unimpaired long-term retrieval. Furthermore, individuals who endorsed either high or low alexithymia equally benefitted from arousal-induced after learning to enhance long-term retrieval of neutral words. The results suggest that the mechanism of action of post-learning memory modulation is physiological arousal response, which was intact in alexithymia. In contrast, the awareness or interpretation of arousal, which was impaired in high alexithymia, did not contribute to memory modulation efficacy.

\section{References}

H.C. Abercrombie, N.H. Kalin, M.E. Thurow, M.A. Rosenkranz, R.J.

Davidson Cortisol variation in humans affects memory for emotionally laden and neutral information Behavioral Neuroscience, 117 (2003), pp. 505-516

R.M. Bagby, J.D.A. Parker, G.J. Taylor The twenty-item Toronto alexithymia scale - I. Item selection and cross-validation of the factor structure Journal of Psychosomatic Research, 38 (1) (1994), pp. 23-32.

R.M. Bagby, G.J. Taylor, J.D.A. Parker The twenty-item Toronto alexithymia scale - II. Convergent, discriminant, and concurrent validity Journal of Psychosomatic Research, 38 (1) (1994), pp. 33-40.

G.G. Berntson, J.T. Cacioppo, K.S. Quigley Autonomic determinism: The modes of autonomic control, the doctrine of autonomic space, and the laws of autonomic constraint Psychological Review, 98 (4) (1991), pp. 459-487

[Consciousness and Cognition, Vol 18, No. 3 (September 2009): pg. 786-793. DOI. This article is @ Elsevier and permission has been granted for this version to appear in e-Publications@Marquette. Elsevier does not grant permission for this article to be further copied/distributed or hosted elsewhere without the express permission from Elsevier.] 
T.W. Buchanan, W.R. Lovallo Enhanced memory for emotional material following stress-level cortisol treatment in humans Psychoneuroendocrinology, 26 (2001), pp. 307-317

L. Cahill, L. Gorski, K. Le Enhanced human memory consolidation with post-learning stress: Interaction with the degree of arousal at encoding Learning and Memory, 10 (4) (2003), pp. 270-274.

S. $-\AA$. Christianson, T. Mjörndal Adrenalin, emotional arousal and memory Scandinavian Journal of Psychology, 26 (1985), pp. 237-248

G.P. Chrousos Stressors, stress, and neuroendocrine integration of the adaptive response. The 1997 Hans Selye Memorial lecture P. Csermely (Ed.), Stress of life. From molecules to man, New York Academy of Sciences, New York (1998), pp. 311-335.

M.G.H. Coles, J.R. Jennings, J.A. Stern (Eds.), Psychophysiological perspectives: Festschrift for Beatrice and John Lacey, Van Nostrand Reinhold, New York (1984).

I.M. Colrain, G.L. Mangan, O.L. Pellett, T.C. Bates Effects of postlearning smoking on memory consolidation Psychopharmacology, 108 (1992), pp. 448-451.

M. Franz, R. Schaefer, C. Schneider, W. Sitte, J. Bachor Visual eventrelated potentials in subjects with alexithymia: Modified processing of emotional aversive information? American Journal of Psychiatry, 161 (4) (2004), pp. 728-735

L. Friedlander, M.A. Lumley, T. Farchione, G. Doyal Testing the alexithymia hypothesis: Physiological and subjective responses during relaxation and stress Journal of Nervous and Mental Disease, 185 (4) (1997), pp. 233-239

[Consciousness and Cognition, Vol 18, No. 3 (September 2009): pg. 786-793. DOI. This article is (C Elsevier and permission has been granted for this version to appear in e-Publications@Marquette. Elsevier does not grant permission for this article to be further copied/distributed or hosted elsewhere without the express permission from Elsevier.] 
P.E. Gold Glucose and age-related changes in memory Neurobiology of Aging, 26 (Suppl. 1) (2005), pp. 60-64.

P.E. Gold, R. van Buskirk Facilitation of time-dependent memory processes with posttrial epinephrine injections Behavioral Biology, 13 (1975), pp. 145-153.

S. Hamann Cognitive and neural mechanisms of emotional memory Trends in Cognitive Sciences, 5 (9) (2001), pp. 394400.

R. Infrasca Alexithymia, neurovegetative arousal and neuroticism. An experimental study Psychotherapy and Psychosomatics, 66 (5) (1997), pp. 276-280.

L.J. Kleinsmith, S. Kaplan Paired-associate learning as a function of arousal and interpolated interval Journal of Experimental Psychology, 65 (2) (1963), pp. 190-193.

J.I. Lacey, J. Kagan, B.C. Lacey, H.A. Moss The visceral level: Situational determinants and behavioral correlates of autonomic response patterns P.H. Knapp (Ed.), Expression of the emotions in man, International Universities Press, New York (1963), pp. 161-196.

P.J. Lang, M.K. Greenwald, M.M. Bradley, A.O. Hamm Looking at pictures: Affective, facial, visceral, and behavioral reactions Psychophysiology, 30 (3) (1993), pp. 261-273.

W. Linden, J.W. Lenz, C. Stossel Alexithymia, defensiveness and cardiovascular reactivity to stress Journal of Psychosomatic Research, 41 (6) (1996), pp. 575-583

D.L.J. Liu, S. Graham, M. Zorawski Enhanced selective memory consolidation following post-learning pleasant and aversive arousal Neurobiology of Learning and Memory, 89 (1) (2008), pp. 36-46

[Consciousness and Cognition, Vol 18, No. 3 (September 2009): pg. 786-793. DOI. This article is (C Elsevier and permission has been granted for this version to appear in e-Publications@Marquette. Elsevier does not grant permission for this article to be further copied/distributed or hosted elsewhere without the express permission from Elsevier.] 
O. Luminet, R.M. Bagby, G.J. Taylor An evaluation of the absolute and relative stability of alexithymia in patients with major depression Psychotherapy and Psychosomatics, 70 (5) (2001), pp. 254-260

O. Luminet, N. Vermeulen, C. Demaret, G.J. Taylor, R.M. Bagby Alexithymia and levels of processing: Evidence for an overall deficit in remembering emotion words Journal of Research in Personality, 40 (5) (2006), pp. 713-733

M.A. Lumley, L. Stettner, F. Wehmer How are alexithymia and physical illness linked? A review and critique of pathways Journal of Psychosomatic Research, 41 (6) (1996), pp. 508-518

L.-G. Lundh, A. Johnsson, K. Sundqvist, H. Olsson Alexithymia, memory of emotion, emotional awareness, and perfectionism Emotion, 2 (4) (2002), pp. 361-379

L.-G. Lundh, M. Simonsson-Sarnecki Alexithymia and cognitive bias for emotional information Personality and Individual Differences, 32 (6) (2002), pp. 1063-1075

S.J. Lupien, C.W. Wilkinson, S. Briere, Y.K. Ng, M.J. Meaney, N.P. Nai rAcute manipulation of aged human memory by pharmacological manipulations of glucocortoids Journal of Clinical Endocrinology \& Metabolism, 87 (2002), pp. 3798-3807

F.S. Maheu, R. Joober, S. Beaulieu, S.J. Lupien Differential effects of adrenergic and corticosteroid hormonal systems on human short- and long-term declarative memory for emotionally arousing material Behavioral Neuroscience, 118 (2) (2004), pp. 420-428

C.A. Manning, M. Parsons, P.E. Gold Anterograde and retrograde enhancement of 24-h memory by glucose in elderly humans Behavioral and Neural Biology, 58 (1992), pp. 125-130 
J.B. Martin, R.O. Pihl The stress-alexithymia hypothesis: Theoretical and empirical considerations Psychotherapy and Psychosomatics, 43 (1985), pp. 169-176

J.B. Martin, R.O. Pihl Influence of alexithymic characteristics on physiological and subjective stress responses in normal individuals Psychotherapy and Psychosomatics, 45 (2) (1986), pp. 66-77

J.L. McGaugh Hormonal influences on memory Annual Review of Psychology, 34 (1983), pp. 297-323

J.L. McGaugh Memory - A century of consolidation Science, 287 (14) (2000), pp. 248-251

McGaugh, J. L., Cahill, L., \& Roozendaal, B. (1996). Involvement of the amygdala in memory storage: Interaction with other brain systems. Proceedings of the National Academy of Sciences of the United States of America, 93, 13508-13514.

M. Mikolajczak, O. Luminet Is alexithymia affected by situational stress or is it a stable trait related to emotion regulation? Personality and Individual Differences, 40 (7) (2006), pp. 13991408

G.E. Müller, A. Pilzecker Experimentelle beitrage zur lehre vom gedachtnis [Experimental contributions in learning and memory] Zeitschrift für Psychologie Erganzungsband, 1 (1900), pp. 1-288

P. Näätänen, A. Ryynänen, L. Keltikangas-Järvinen The influence of alexithymic characteristics on the self-perception and facial expression of a physiological stress state Psychotherapy and Psychosomatics, 68 (5) (1999), pp. 252-262

S.A. Neumann, J.J. Sollers 3rd, J.F. Thayer, S.R. Waldstein Alexithymia predicts attenuated autonomic reactivity, but

[Consciousness and Cognition, Vol 18, No. 3 (September 2009): pg. 786-793. DOI. This article is @ Elsevier and permission has been granted for this version to appear in e-Publications@Marquette. Elsevier does not grant permission for this article to be further copied/distributed or hosted elsewhere without the express permission from Elsevier.] 
prolonged recovery to anger recall in young women International Journal of Psychophysiology, 53 (3) (2004), pp. 183-195

T. Newton, R.J. Contrada Alexithymia and repression: Contrasting emotion-focused coping styles Psychosomatic Medicine, 56 (1994), pp. 457-462

K.A. Nielson, T. Bryant The effects of non-contingent extrinsic and intrinsic rewards on memory consolidation Neurobiology of Learning and Memory, 84 (2005), pp. 42-48

K.A. Nielson, R.A. Jensen Beta-adrenergic receptor antagonist antihypertensive medications impair arousal-induced modulation of working memory in elderly humans Behavioral and Neural Biology, 62 (1994), pp. 190-200

K.A. Nielson, M. Powless Positive and negative sources of emotional arousal enhance long-term word-list retention when induced as long as thirty minutes after learning Neurobiology of Learning and Memory, 88 (2007), pp. 40-47

K.A. Nielson, R.C. Radtke, R.A. Jensen Arousal-induced modulation of memory storage processes in humans Neurobiology of Learning and Memory, 66 (1996), pp. 133-142

K.A. Nielson, D. Yee, K.I. Erickson Memory enhancement by a semantically unrelated emotional arousal source induced after learning Neurobiology of Learning and Memory, 84 (2005), pp. 49-56

P.A. Obrist Cardiovascular psychophysiology: A perspective Plenum Press, New York (1981)

A. Öhmann, A.O. Hamm, K. Hugdahl Cognition and the autonomic nervous system: Orienting, anticipating, and conditioning J.T. Cacioppo, L.G. Tassinary, G.G. Berntson (Eds.), Handbook of psychophysiology, Cambridge University Press, New York (2000), pp. 533-575

[Consciousness and Cognition, Vol 18, No. 3 (September 2009): pg. 786-793. DOI. This article is (C) Elsevier and permission has been granted for this version to appear in e-Publications@Marquette. Elsevier does not grant permission for this article to be further copied/distributed or hosted elsewhere without the express permission from Elsevier.] 
A.S. Papciak, M. Feuerstein, J.A. Spiegel Stress reactivity in alexithymia: Decoupling of physiological and cognitive responses Journal of Human Stress, 11 (3) (1985), pp. 135142

J. Quevedo, M.K. Sant' Anna, M. Madruga, I. Lovato, F. de-Paris, F. Kapczinski, et al.Differential effects of emotional arousal in short- and long-term memory in healthy adults Neurobiology of Learning and Memory, 79 (2) (2003), pp. 132135

W. Revelle, D.A. Loftus The implications of arousal effects for the study of affect and memory S. Christianson (Ed.), The handbook of emotion and memory, Lawrence Erlbaum Assoc, Hillsdale (1992), pp. 113-150

T.M. Roedema, R.F. Simons Emotion-processing deficit in alexithymia Psychophysiology, 36 (1999), pp. 379-387

P.E. Sifneos The prevalence of 'alexithymic' characteristics in psychosomatic patients Psychotherapy and Psychosomatics, 22 (1973), pp. 255-262

S.M. Southwick, M. Davis, B. Horner, L. Cahill, C.A.r. Morgan, P.E. Gold, et al. Relationship of enhanced norephinphrine activity during memory consolidation to enhanced longterm memory in humans American Journal of Psychiatry, 159 (2002), pp. 1420-1422

L.A. Stone, K.A. Nielson Intact physiological response to arousal with impaired emotional recognition in alexithymia Psychotherapy and Psychosomatics, 70 (2001), pp. 92-102

C. Subic-Wrana, S. Bruder, W. Thomas, R.D. Lane, K. Kohle Emotional awareness deficits in inpatients of a psychosomatic ward: A comparison of two different measures of alexithymia Psychosomatic Medicine, 67 (3) (2005), pp. 483-489 
T. Suslow, A. Kersting, V. Arolt Alexithymia and incidental learning of emotional words Psychological Reports, 93 (3, Pt2) (2003), pp. 1003-1012

G.J. Taylor The alexithymia construct: Conceptualization, validation, and relationship with basic dimensions of personality New Trends in Experimental and Clinical Psychiatry, 10 (2) (1994), pp. 61-74

G.J. Taylor Recent developments in alexithymia theory and research Canadian Journal of Psychiatry, 44 (2000), pp. 134142

G.J. Taylor, R.M. Bagby, J.D.A. Parker The alexithymia construct: A potential paradigm for psychosomatic medicine Psychosomatics, 32 (2) (1991), pp. 153-164

G.J. Taylor, R.M. Bagby, J.D.A. Parker Disorders of affect regulation: Alexithymia in medical and psychiatric illness Cambridge University Press, Cambridge, UK (1997)

G.J. Taylor, H.L. Taylor Alexithymia M. McCallum, W.E. Piper (Eds.), Psychological mindedness: A contemporary understanding, Lawrence Erlbaum Associates, Mahway, NJ (1997), pp. 77-104

M. Torras-Garcia, I. Portell-Cortes, D. Costa-Miserachs, I. MorgadoBernal Long-term memory modulation by posttraining epinephrine in rats differential effects depending on the basic learning capacity Behavioral Neuroscience, 111 (1997), pp. 301-308

L.J. Varner, H.C. Ellis Cognitive activity and physiological arousal: Processes that mediate mood-congruent memory Memory and Cognition, 26 (5) (1998), pp. 939-950

E.L. Walker Action decrement and its relation to learning Psychological Review, 65 (1958), pp. 129-142 
NOT THE PUBLISHED VERSION; this is the author's final, peer-reviewed manuscript. The published version may be accessed by following the link in the citation at the bottom of the page.

F. Wehmer, C. Brejnak, M. Lumley, L. Stettner Alexithymia and physiological reactivity to emotion-provoking visual scenes Journal of Nervous and Mental Disease, 183 (6) (1995), pp. 351-357

R. Yerkes, J. Dodson The relation of strength of stimulus to rapidity of habit-formation Journal of Comparative Neurology and Psychology, 18 (1908), pp. 459-482 